\title{
DISPUTE ANALYSIS OF CLAIMS FOR COVID-19 PATIENTS AT HOSPITALS OF INDONESIA UNIVERSITY
}

\author{
Rakhmad Hidayat'), Budi Hidayat ${ }^{2)}$ \\ 1)Administrative Studies, Faculty of Public Health, Universitas Indonesia \\ 2)Faculty of Public Health, Universitas Indonesia
}

\begin{abstract}
Background: Indonesia is one of the countries affected by COVID-19 pandemic. In overcoming this pandemic, the government waives the service fees for COVID-19 patients. It provides an opportunity for hospitals serving COVID-19 patients to submit claims for treatment financing to the Ministry of Health. There are technical guidelines for payment; there are still frequent problems, leading to a dispute. This is also experienced by the University of Indonesia Hospital (RSUI) as one of the COVID-19 referral hospitals. This study aimed to provide an overview of the claim problem encountered and their solution.

Subjects and Method: This was a descriptive study conducted at University of Indonesia Hospital from July, 2020. The theme of this study was problem in claiming payments for COVID-19 patients. Several informants were selected for this study included: hospital claim officers, medical record units, inpatient units and registration units. The data were collected by observation, in-depth interview, disputed claim data.

Results: The results of the investigation found that the problem of dispute claims for COVID-19 in RSUI was dominated by the incompleteness of filling in administrative files as evidence of service practice for patients in the field, such as incomplete ventilator usage curves (7.8\%), swab results (3.9\%), and rapid test (6.8\%) which was not listed.

Conclusion: Discipline needs to be applied in the completeness of documents, and a clear flow of patient care is required to avoid incomplete records.
\end{abstract}

Keywords: dispute, claim, COVID-19, hospital, health insurance

\section{Correspondence:}

Rakhmad Hidayat. Pascasarjana Kajian Administrasi, Fakultas Kesehatan Masyarakat Universitas Indonesia, Pondok Cina, Kecamatan Beji, Kota Depok, Jawa Barat 12345. Email:

rhidayat.md@gmail.com. Mobile: (021) 7864975

BACKGROUND
World Health Organization (WHO) has
designated COVID-19 as a world pandemic.
Until Aug 6, 2020, in Indonesia, COVID-19
has infected more than 100 thousand people
and caused death to more than 50oo people.
With the designation of COVID-19 as a
pandemic, the government is taking several
steps in dealing with this non-natural
disaster. One of the government's strategies
is to pay the service fee for COVID-19
patients to the hospital that is a referral so
that there are no problems with treatment.

In light of the Decree of the Minister of Health of the Republic of Indonesia Number HK 01.07/MENKES/238/2020 concerning Technical Guidelines for Claims for Reimbursement of Treatment Costs for Certain Emerging Infectious Diseases Patients for Hospitals Providing Services for Coronavirus Disease 2019 (COVID-19), COVID-19 reference emergency clinics and homes other wiped out individuals who offer types of assistance for COVID-19 patients can submit claims for financing COVID-19 patients to the Ministry of Health through

The $7^{\text {th }}$ International Conference on Public Health Solo, Indonesia, November 18-19, $2020 \mid 40$ https://doi.org/10.26911/the7thicph-FP.04.06 
the Director-General of Health Services. Patients whose treatment costs can be claimed are people under surveillance (ODP), patients under supervision (PDP), and patients who have been confirmed with COVID-19 (Ministry of Health, 2020).

Cost claims can be submitted collectively to the Director-General of Health Services, which will later be copied to BPJS Health for verification and to the regional health office. File claims submitted can be uploaded online. The required files include a Statement of Absolute Responsibility (SPTJM), patient recapitulation, Work Order (SPK) Payment of Service Bill Claims, and completeness of signatures. Claims can be submitted per 14 working days. If there is a lack of data for submitting claims, BPJS will return the hospital's request to be completed and raised again by the hospital. If there is a claim dispute after verification by BPJS, a team formed by the Minister of Health will make a settlement. BPJS Health will issue a News Acar Verification of Claim Payment no later than 7 days after receiving the claim. The Ministry of Health will give the next payment within 3 working days after receipt of the minutes (Ministry of Health, 2020).

The University of Indonesia Hospital (RSUI) is a type B hospital located in Depok City. It has been designated as one of the COVID-19 referral hospitals and the Dedicated Hospital for handling COVID-19 based on the Circular of the Ministry of Health Number: HK.02.02/I/0883/2020 concerning the COVID-19 Service Network in Hospitals for Providing Non-Referral PIE Services and the Decree of the Mayor of Depok Number: 440/140/Kpts/Dinkes/Huk/2020. As of June 2020, RSUI has treated 213 patients under surveillance (PDP) and confirmed patients. RSUI is one of the hospitals that has also implemented a claim payment system for COVID-19 patients to the Ministry of Health. Even with the government's technical guidelines, the implementation of claim payments still faces several obstacles. There was a dispute in collecting claims for compensation of COVID-19 patients, which has the potential to hamper optimal service for COVID-19 patients. This article will discuss the problems faced by COVID-19 referral hospitals in submitting payment claims for COVID-19 patients.

\section{SUBJECTS AND METHOD \\ 1. Study Design}

This was a descriptive study conducted at the University of Indonesia Hospital in July 2020.

\section{Study Variables}

The theme of this study was a problem in claiming payments for COVID-19 patients.

\section{Data collection}

Several informants were selected for this study included: hospital claim officers, medical record units, inpatient units, and registration units. The data were collected by observation, in-depth interview, and disputed claim data.

\section{RESULTS}

Since the establishment of RSUI as one of the hospitals, RSUI has treated 213 PDP and confirmed patients. One hundred and two claims have been processed, and 55 licenses are in the process of filing claims. Of the 102 claims submitted, 50 claims (49.1\%) have reached the final stage, and 52 others (50.9\%) are still in dispute. From these findings, RSUI is investigating the obstacles faced by related parties, and the following are the findings of problems in the process of submitting COVID-19 claims at referral hospitals during the COVID-19 period:

The $7^{\text {th }}$ International Conference on Public Health

Solo, Indonesia, November 18-19, $2020 \mid 41$ https://doi.org/10.26911/the7thicph-FP.04.06 
Table 1. Problems faced

\begin{tabular}{llcc}
\hline No & \multicolumn{1}{c}{ Problem } & $\begin{array}{c}\text { Number } \\
\text { (n= 52) }\end{array}$ & Percentage (\%) \\
\hline 1 & $\begin{array}{l}\text { Swab test (have/not) } \\
2\end{array}$ & 4 & $3.9 \%$ \\
3 & $\begin{array}{l}\text { Rapid test not attached } \\
\text { Evidence of ventilator use is not included }\end{array}$ & 7 & $6.8 \%$ \\
4 & $\begin{array}{l}\text { Supporting evidence for comorbid diagnosis/- } \\
\text { evidence incomplete support }\end{array}$ & 5 & $7.8 \%$ \\
5 & $\begin{array}{l}\text { Billing different room with the space used and billing } \\
\text { other from the date return of medical records }\end{array}$ & 3 & $2.9 \%$ \\
6 & $\begin{array}{l}\text { Patients go home after negative results have been out } \\
\text { a few days earlier }\end{array}$ & 3 & $2.9 \%$ \\
7 & $\begin{array}{l}\text { The first swab test was done after the treatment } \\
\text { (delayed) }\end{array}$ & 4 & $3.9 \%$ \\
8 & $\begin{array}{l}\text { RSUI health workers who suffer from COVID-19 } \\
\text { cannot be claimed to the Ministry of Health }\end{array}$ & 5 & $4.9 \%$ \\
\hline $\begin{array}{l}\text { Evidence of transfer of moving rooms/IGD/SPR } \\
\text { observation sheets missing or unclear }\end{array}$ & 4 & $3.9 \%$ \\
10 & $\begin{array}{l}\text { Different administrative data with ID number } \\
\text { Initial screening results before hospitalization were } \\
\text { absent or unclear }\end{array}$ & 7 & $1.9 \%$ \\
\hline
\end{tabular}

The reasons for rejection of claims were mostly due to the absence of supporting documents for ventilators. Also, the absence of screening and rapid test results at the beginning of treatment was also found. Based on these findings, RSUI has formulated several solutions in dealing with these problems which are described in the discussion section.

\section{DISCUSSION}

1. Swab test (have/not)

Swab results are an essential aspect of the diagnosis of COVID-19. All patients hospitalized with a diagnosis of suspected/probable/confirmed COVID-19 must have an RT-PCR swab on the first and second day of treatment for the diagnosis. If there is clinical improvement, then the next swab is carried out on the seventh day since the first entry to assess cure ( Ministry of Health, 2020).
}

To avoid long or absent swab results, cooperation from various parties is needed, such as the doctor in charge of the patient (DPJP), general practitioners, nurses, laboratories, and medical records. DPJP plays a role in ensuring that swabs are carried out on the first and second day of treatment for diagnosis, ensuring that the next swab (for patients with severe/critical symptoms) is carried out on the seventh day to assess recovery if the patient experiences clinical improvement, and make changes in KDP so that the type and type and RT-PCR swab interval according to KMK 413/2020 (Ministry of Health, 2020).

General practitioners can assist DPJP in ensuring swabs are carried out on the first and second day of treatment for diagnosis and ensure that the next swab (for patients with severe/critical symptoms) is done on the seventh day to assess recovery if the patient experiences clinical improvement. Nurses play a role in coordinating with

The $7^{\text {th }}$ International Conference on Public Health Solo, Indonesia, November 18-19, $2020 \mid 42$ https://doi.org/10.26911/the7thicph-FP.04.06 
laboratories and general practitioners regarding the implementation of swabs. The laboratory should also make sure that the samples received are processed quickly so on the second day after receiving the samples. The medical record is responsible for ensuring that the patient swab results during the complete treatment.

Patients with suspected/probable/confirmed COVID-19

RT-PCR swab test on the second and third day

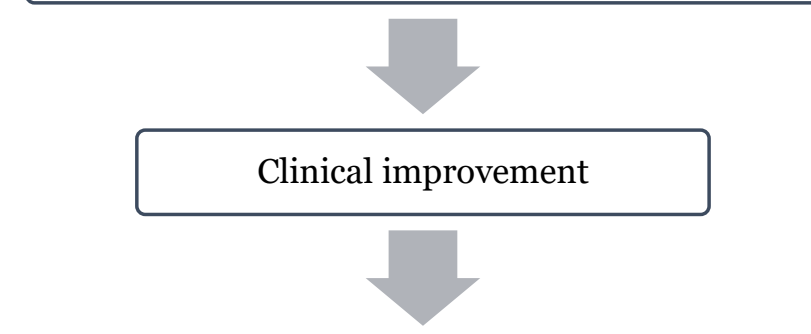

Swab on the seventh day after entry for evaluation

that the results of the swabs can be available

\section{Figure 1. PCR examination flow}

\section{Rapid Test not Attached}

Rapid tests are rapid tests for COVID-19 antibodies that can be used as initial detection of suspected COVID-19 patients (WHO, 2020). If a patient is admitted to the Suspect/Probable COVID-19 category, the results of the SARS-CoV-2 antibody rapid test must be available from the referring hospital; or if the patient is tested for SARSCoV-2 antibody rapid tests during the treatment period.

DPJP, doctors and nurses a role in extracting information from suspect/probable COVID-19 patients regarding SARS-CoV-2 antibody rapid test results from the referring hospital and entering it into the patient's medical record (CPPT) and attached to the RM manual. Besides, medical records also play a role in ensuring the patient's rapid test results before and during the hospitalization period are fully available in the RM document before they are discharged from hospital/emergency room.

3. Evidence of using a Ventilator COVID-19 has various clinical manifestations and degrees of severity. A report by Yang et al. (2020) on 710 confirmed cases of SARS-CoV-2 in Wuhan, 52 patients were in critical condition, and $71 \%$ (37 patients) required mechanical ventilation. Considering the high risk of ventilation, hospitals must prepare sufficient and adequate ventilators for COVID-19 patients.

The payment claim system to the Ministry of Health requires attached proof of ventilator use. This evidence can be in the form of a clinical monitoring curve during the use of a ventilator. This encourages nurses to fill in the complete clinical monitoring curve in the ICU, especially for COVID-19 patients who are on ventilators. Patient monitoring data on a ventilator must 
be included in filing a claim for a COVID-19 patient.

\section{Supporting Evidence for Comorbid Diagnosis/Incomplete Supporting Evidence}

The presence of comorbid in patients suffering from COVID-19 can affect outcomes. According to research from Sanyaolu et al. (2020), COVID-10 patients who have comorbidities such as hypertension or diabetes mellitus are at risk of worsening and a worse prognosis. Thus, patients with COVID-19 who have comorbid need special attention.

In maintaining administrative order, it is not enough to attach supporting evidence from the related unit, but comorbid diagnosis and supporting evidence must also be included in the patient discharge summary. DPJP is responsible for completing the home summary contents and can be assisted by the on-duty doctor in achieving the medical resume. The medical record must also ensure a complete summary of the patient's discharge with the results of examinations supporting the comorbid diagnosis.

\section{Room Billing is Different from Medical Records}

Writing errors that often occur, for example, in uploading claims files for treatment rooms in isolation, but on bills for patients hospitalized in the ICU. To avoid writing errors, regulations need to be made, so that room names and room rates for COVID-19 are appropriate. For example, in RSUI, all 3 floors are ICU harmful pressure isolation, while apart from the 3rd floor are unfavorable pressure COVID-19 isolation rooms. This naming must be the same in billing and patient medical records.

In this case, admission officers play a role in ensuring that patients are registered in a room that meets the needs as requested by the DPJP. DPJP is tasked with filling out the inpatient certificate completely so that patients can be recorded in the room according to the diagnosis and degree of disease severity.

\section{Patients go home after negative results have been out a few days earlier}

To overcome this, the DPJP plays a role in the re-education of patients/families regarding the financing options for patients with comorbid/complications that have not been resolved but have been declared complete isolation. DPJP must ensure that ODP/PDP/Confirmation + comorbid patients are stable + repair radiology + positive/negative PCR + Rapid reactive/non-reactive tests can return a maximum of $\mathrm{H}+1$ after being declared allowed to go home.

In addition, DPJP and general practitioners also need to ensure that ODP/PDP/Confirmation + comorbid patients are not stable + PCR negative or Rapid non-reactive to move to non-isolation ward rooms (COVID-19 coverage ends, must change to JKN /Insurance/Independent), patients People in monitoring/ patients who show symptoms of being infected with the corona virus/Confirmation + resolved complications + radiological repair + PCR positive / negative + Rapid reactive / nonreactive test can go home a maximum of $\mathrm{H}+$ 1 since it is declared that you can go home. People in monitoring/ patients who show symptoms of being infected with the corona virus/ Confirmation + complications have not been resolved + PCR negative or Rapid non-reactive must also be confirmed to move to a non-isolation ward (COVID-19 coverage ends, must change to JKN / Insurance / Mandiri).

The admission officer must also play a role in helping the process of returning 
patients who have been declared allowed to go home by the DPJP so that they can be completed a maximum of $\mathrm{H}+1$ since they are declared allowed to go home by the DPJP

7. The First Swab Test was done after The Treatment (Delayed)

All patients hospitalized with a suspected confirmation of COVID-19 should be done with RT-PCR swab on the first and second day of treatment for the diagnosis. If there is clinical improvement, then the next swab is done on the seventh day since the first entry to assess the cure.

There should be uniformity regarding the type of specimen and the timing of swab collection (day 1 and 2 for diagnosis, day 7 for evaluation) in all KDP. Including emergency room patients whose indications for hospitalization are full (stagnant patient procedure), the first and second-day swabs should not be postponed.

\section{RSUI health workers who suffer from COVID-19 cannot be claimed at the Ministry of Health}

Claims for health workers treated and diagnosed with COVID-19 refer to the PAK (occupational disease) claim process to BPJS-TK. This process is separate from claiming COVID-19 to the Ministry of Health, but the focus on completeness of medical record files, supporting examinations, and medical resumes remain the same.

\section{Evidence of transfer of moving rooms/IGD/SPR observation sheets missing or unclear}

Evidence of communication between rooms of patients must be complete and written stored in medical records. While the patient is being monitored in the ER, the observation sheet must be entire and kept in medical history. Inpatient Request Letter (SPRI) must be complete and written clearly: a. Main diagnosis: suspected/probable/confirmation of COVID-19, including grading severity of disease (mild, moderate, severe, critical), see KMK HK.01.07 / MENKES / 413 / 2020 pages 87-88

b. Secondary diagnosis must be included in SPRI Admission.

\section{Different Administrative Data with} ID Number

Officers have a role in ensuring complete proof of patient identity and communicating with superiors if there is a patient identity problem. Proof of identity required, namely for foreigners: passport, KITAS or UNHCR identity number; for Indonesian citizens: Identity Number (NIK), family card, or a certificate from the sub-district; and for displaced people: a certificate from the social service.

Suppose all identities as referred to in number 1 cannot be shown. In that case, proof of identity can use a patient data certificate signed by the head of the district or city health office and affixed with the regency or city health service stamp. The hospital submits a patient data certificate from the district/city health office to the district/city health office.

For this reason, the provincial/district/city health office must prepare a list of Corona Virus Disease 2019 (COVID-19) patients in the work area or check the patient list through the Public Health Emergency Operating Center (PHEOC) from the local district/city health office. If all identities referred to in numbers 1 and 2 cannot be shown, proof of identity can use a Certificate/Service Guarantee (SJP) from the hospital leadership.

11. Initial Screening Results before Hospitalization were Absent or Unclear 
Initial screening of patients is determined as patients who show symptoms of being infected with the corona virus (COVID-19) confirmation must be available, can be:

a. Evidence of COVID-19 screening in the ER triage.

b. Results of SARS-CoV-2 antibody rapid test

c. Results from Current SARS-CoV-2 PCR swab examination

All of the above evidence must be entered as part of the patient's medical record, which will later be attached to the claim file. Screening can use a series of activities such as checking body temperature with a thermal gun, simple questions such as fever or history of fever, cough, sore throat, nasal congestion, shortness of breath, malaise, headache, muscle pain, history of close contact with the patient confirmation and account. Travel within 14 days from the country or local transmission area to get the patient's initial status for the presence or absence of symptoms of COVID-19.

Table 2. Problems and solutions

\begin{tabular}{|c|c|c|c|}
\hline No & Problem & Solutions & $\begin{array}{c}\text { Responsible } \\
\text { Agency }\end{array}$ \\
\hline 1 & $\begin{array}{l}\text { Results of swab } \\
\text { time/none }\end{array}$ & $\begin{array}{l}\text { must be uniformity regarding the type of } \\
\text { specimen and the time for taking the swab } \\
\text { (day one and day two for diagnosis, day } \\
\text { seventh for evaluation) in all KDP }\end{array}$ & $\begin{array}{ll}\text { - } & \text { Doctor in charge } \\
\text { - } & \text { Nurses } \\
\text { - } & \text { Laboratory } \\
\text { - } & \text { Medical records }\end{array}$ \\
\hline 2 & $\begin{array}{l}\text { Results of rapid tests are } \\
\text { not attached }\end{array}$ & $\begin{array}{l}\text { All results of the SARS-CoV-2 antibody } \\
\text { rapid test must be attached either from the } \\
\text { referring hospital or at the hospital during } \\
\text { the treatment period. }\end{array}$ & $\begin{array}{l}\text { - } \text { Doctor in charge } \\
\text { - Nurse } \\
\text { - Laboratory } \\
\text { - } \text { Medical records }\end{array}$ \\
\hline 3 & $\begin{array}{l}\text { Evidence of ventilator } \\
\text { use is not included. }\end{array}$ & $\begin{array}{l}\text { Clinical monitoring curves during the use } \\
\text { of the ventilator in ICU patients should be } \\
\text { attached. }\end{array}$ & $\begin{array}{ll}\text { - } & \text { Nurse } \\
\text { - } & \text { Medical records }\end{array}$ \\
\hline 4 & $\begin{array}{l}\text { Supporting evidence for } \\
\text { comorbid } \\
\text { diagnosis/incomplete }\end{array}$ & $\begin{array}{l}\text { Supporting evidence. Comorbid diagnosis } \\
\text { and supporting evidence should also be } \\
\text { included in the patient discharge } \\
\text { summary. }\end{array}$ & $\begin{array}{l}\text { - Doctor in charge } \\
\text { - } \text { Medical record }\end{array}$ \\
\hline
\end{tabular}

Based on the above discussion, it can be seen that the dispute over the COVID-19 claim at RSUI is dominated by incomplete administrative documents filling as evidence of service practice for patients in the field. Regarding the issuance of KMK HK.01.07/MENKES/413/2020, adjustments to PPK COVID-19 in various RSUI patients' populations need to be made, especially regarding hospitalization criteria, diagnosis by swab, discharge criteria, and criteria for patients to be considered complete isolation. Discipline needs to be applied in determining the requirements for completion of isolation for patients with comorbid / complication/coincidence. The author also recommends making a service flow for COVID-19 patients that is clear and with a clear division of responsibilities so that there are no shortages in filling out documents. 
DPJP is responsible for the completeness of the home summary contents and can be assisted by the on-duty doctor in completing the medical resume.

5 Billing for different rooms with the space used and billing for the return date is different from medical records

Patients go home after negative results have come out a few days earlier

The first swab is done a few days after treatment (delayed)

RSUI health workers who suffer from COVID-19 cannot be claimed to the Ministry of Health.

Evidence of transfer of moving rooms/sheets IGD/SPR observation does not exist or is not clear

Different administrative data with NIK
Required re-classification of unique treatment rooms for COVID and necessary pay attention to the impact of space naming on the information listed in the billing and patient's medical record (must be the same).

In ODP/PDP/Confirmation patients and comorbid is a stable and radiological improvement, negative PCR, and ODP/PDP/ confirmed patients with complications resolved, radiological improvement and positive/negative PCR and reactive/non-reactive rapid test can be declared home. The length of treatment can be increased by a maximum of one day after being declared ready to go home.

Patients with unstable comorbidities with negative PCR results and patients with unresolved complications can be moved to a non-isolation room and change their insurance to $\mathrm{JKN} /$ insurance/independent.

There should be uniformity regarding the type of specimen and swab collection time (first and the second day for diagnosis, a seventh day for evaluation) in all KDP.

Claims for health workers who are treated and diagnosed with COVID-19 refer to the PAK claim process to BPJS-TK

Evidence of communication between patient movement between rooms must be complete and written, stored in medical records

Ensure complete proof of patient identity and communicate with superiors if there is a problem with the patient's identity
- Admission officer

- Doctors in charge

- Inpatient and outpatient managers

- Admission officer

- Doctor in charge of patient

- General practitioner
- Doctor in charge

- General doctors

Admission officer

- General practitioner

- Nurse - Admission officer 


\begin{tabular}{llrlll}
\hline 11 & $\begin{array}{l}\text { Results of } \\
\text { screening }\end{array}$ & $\begin{aligned} \text { initial } \\
\text { before }\end{aligned}$ & $\begin{array}{l}\text { Ensuring that the patient's initial } \\
\text { screening is determined as PDP / COVID- }\end{array}$ & $\bullet$ & Doctor in charge \\
hospitalization & are & 19 confirmation must be available and & $\bullet$ & Nurses \\
missing or unclear & & attached to the patient's medical record. & $\bullet$ & Medical records \\
\hline
\end{tabular}

To get around this claim dispute, we propose the following service flow for COVID-19 patients:

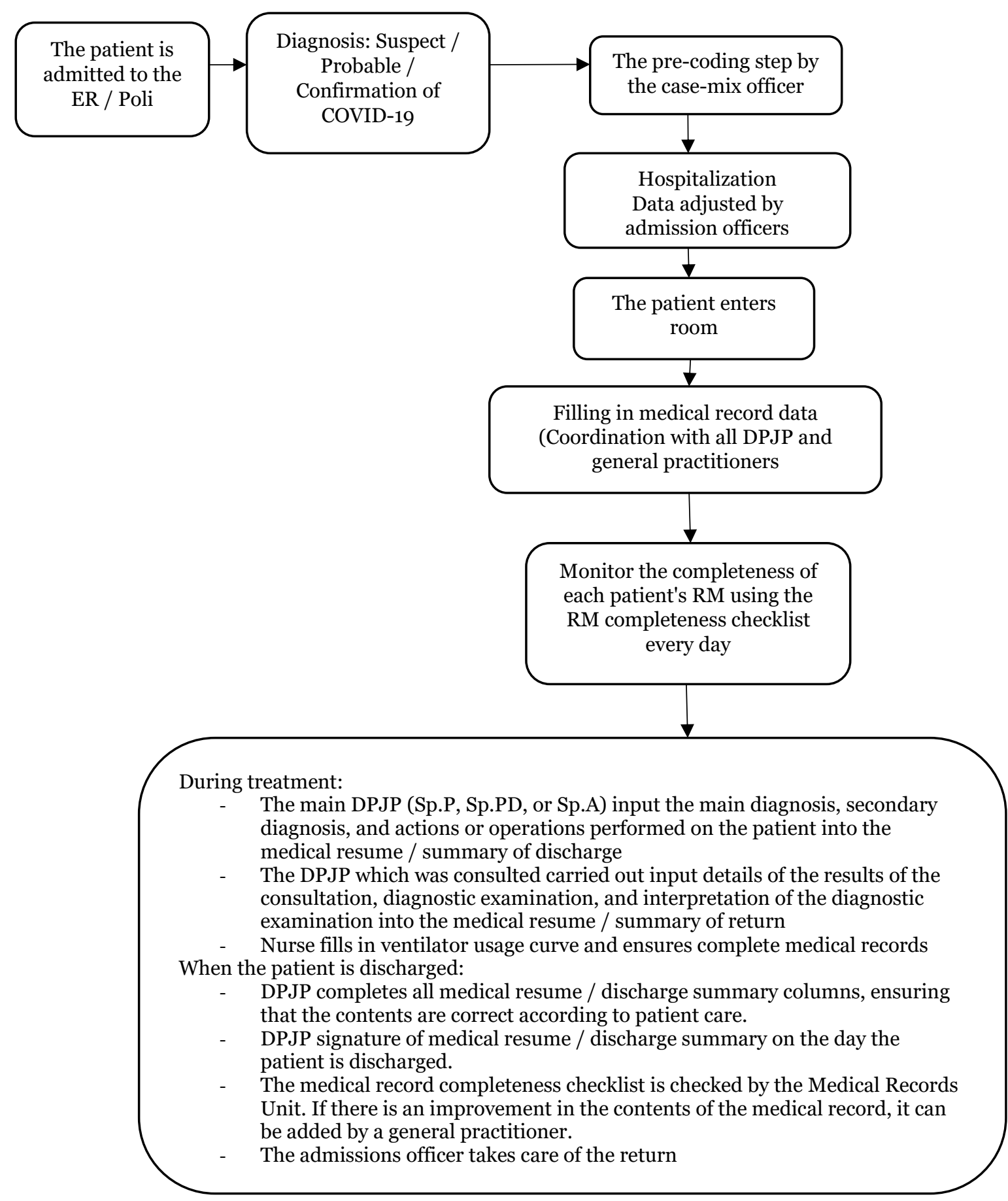

The $7^{\text {th }}$ International Conference on Public Health Solo, Indonesia, November 18-19, $2020 \mid 48$ https://doi.org/10.26911/the7thicph-FP.04.06 


\section{Figure 2. The flow of services for COVID-19 patients}

\begin{tabular}{l}
\hline REFERENCES \\
\hline Indonesian Ministry of Health. 2020. \\
Decree of the Minister of Health of the \\
Republic of Indonesia Number \\
Hk.01.07/Menkes/413/2020 concern- \\
ing Guidelines for the Prevention and \\
Control of Coronavirus Disease 2019 \\
(Covid-19), \\
Ministry of Health of Indonesia. 2020. \\
Decree of the Minister of Health of the \\
Republic of Indonesia Number \\
Hk.01.07/Menkes/238/2020 concer- \\
ning Technical Guidelines for Claims \\
for Reimbursement of Treatment \\
Costs for Certain Emerging Infectious \\
Diseases Patients for Hospitals \\
Organizing Services for Coronavirus \\
Disease 2019 (Covid-19) \\
Indonesian Ministry of Health. 2020. \\
Guidelines for the Control and
\end{tabular}

Prevention of Coronavirus Disease (Covid-19).

Sanyaolu A, Okorie C, Marinkovic A, Patidar R, Younis K, Desai P, Hosein Z et al. (2020). Comorbidity and Its Impact on Patients with Covid-19. Sn Compr Clin Med. 1-8. Doi: 10.1007 / S42399020-00363-4. Pmcid: Pmc7314621.

World Health Organization (2020). Suggestions for the Use of Immunodiagnostic Tests in Health Care Facilities (Point Of Care) for Covid-19: Scientific Statements

Yang X, Yu Y, Xu J, Shu H, Xia J, Liu H, Wu $\mathrm{Y}$, et al. (2020). Clinical course and outcomes of critically ill patients with SARS-CoV-2 pneumonia in Wuhan, China: a single-centered, retrospective, observational study. The Lancet Respiratory Medicine, 8 (5), pp.475481. 